\title{
Formação para gestão de organizações culturais e artísticas: uma pesquisa exploratória
}

\section{Training for management of cultural and artistic organizations: an exploratory research}

\author{
DOI: $10.46814 /$ lajdv3n5-037
}

Recebimento dos originais: 01/05/2021

Aceitação para publicação: 31/06/2021

\author{
Romero de Albuquerque Maranhão \\ Pós-Doutor em Educação, Arte e História da Cultura pela Universidade Presbiteriana Mackenzie. \\ Instituição: Universidade Presbiteriana Mackenzie. \\ Endereço: Rua da Consolação, 930 - Consolação, São Paulo - SP, 01302-907. \\ E-mail: romeroalbuquerque@bol.com.br
}

\begin{abstract}
RESUMO
Em boa parte do território brasileiro há uma escassez de gestores para as organizações culturais e artísticas. Tal problema é acarretado, em parte, pela deficiência na formação dos gestores e, também, dos artistas, bem como pelas dificuldades em formar profissionais numa lógica interdisciplinar. Neste contexto, esta pesquisa exploratória e explicativa visa discutir os obstáculos e os desafios a serem enfrentados pelos gestores e pelos artistas para a inserção no mercado de trabalho, a partir de uma revisão bibliográfica, documental e entrevistas com acadêmicos, gestores e artistas. Os resultados preliminares apontam que a oferta de ensino de administração e de artes no Brasil é ampla. Contudo, na área de administração, seu foco na maioria das vezes é formar pessoas capacitadas para ocupar cargos de gestão como funcionários em áreas de conhecimento mais voltadas a atender às necessidades de grandes organizações. E na área de artes, qualificar profissionais que possam se expressar nas diversas linguagens artísticas. Desta forma, há uma carência de cursos que contemplem conhecimentos de gestão, produção cultural e arte para contribuir na formação de profissionais de carreiras artísticas e gestores. Conclui-se que os conhecimentos de produção e gestão de organizações culturais e artísticas, por também contribuírem com a noção de "organização" presente na ciência administrativa, proporcionam aos profissionais das carreiras artísticas ferramentas para estruturar e gerenciar suas atividades laborais.
\end{abstract}

Palavras-chave: gestão cultural; marketing; mercado de arte.

\begin{abstract}
In much of Brazil there is a shortage of managers for cultural and artistic organizations. This problem is caused, in part, by the deficiency in the training of managers and also by artists, as well as by the difficulties in training professionals in an interdisciplinary logic. In this context, this exploratory and explanatory research aims at discussing the obstacles and challenges to be faced by managers and artists for insertion in the labor market, based on a bibliographical review, documentary and interviews with academics, managers and artists. The preliminary results indicate that the offer of teaching of administration and arts in Brazil is ample. However, in the area of management, the focus is most often on training people to hold management positions as employees in knowledge areas that are more geared to meeting the needs of large organizations. And in the area of arts, qualify professionals who can express themselves in the various artistic languages. In this way, there is a lack of courses that contemplate knowledge of management, cultural production and art to contribute in the formation of professionals of artistic careers and managers. It is concluded that the knowledge of production and
\end{abstract}


management of cultural and artistic organizations, as they also contribute to the notion of "organization" present in the administrative science, provide professionals of the artistic careers with tools to structure and manage their work activities.

Keywords: cultural management; marketing; art market.

\section{CONSIDERAÇÕES INICIAIS}

Depois da $2^{\text {a }}$ Guerra Mundial, registrou-se grande desenvolvimento das instituições artísticas e culturais, merecendo as mesmas, grandes apoios por parte dos Governos. As organizações do setor cultural têm crescido e despertado a atenção de empresas privadas (nacionais e internacionais) e de Organizações Não Governamentais (ONG) que veem, nestas organizações, uma forma de obter relevância social (JESUS, 2017; STORI e MARANHÃO, 2017; MARANHÃO e STORI, 2018; MARTINS, 2021).

A Gestão das Organizações do setor cultural e artístico é um fenômeno relativamente recente na História das Artes e da Gestão, tendo surgido, sobretudo nos países com economias mais estáveis, onde a Cultura e a Produção Artística são entendidas como bens econômicos em si e, sobretudo, como processos geradores de desenvolvimento social (em toda a sua amplitude), sendo encarada como um meio imprescindível na implementação, crescimento e afirmação da criação artística junto dos públicos e dos agentes econômicos (MARANHÃO e STORI, 2019a; MARANHÃO e STORI, 2019b).

Apesar de o trabalho artístico fundamentar-se em princípios muitas vezes antagônicos aos do mercado e esteja mais associado à produção de cultura ${ }^{1}$ e ao interesse público, ele pode ser igualmente concebido como um serviço capaz de gerar lucro. Como em qualquer outro setor, isso ocorrerá na medida em que o setor possuir estratégias de gestão voltadas para atender suas especificidades e profissionais preparados e com visão (VALENTE et al., 2007).

No Brasil há mais de 3.000 museus, 1.229 teatros, 4.950 bibliotecas, cerca de 2.000 companhias circenses e mais de 700 escolas de samba, dentre outras organizações artísticas e culturais (STORI e MARANHÃO, 2017).

Assim, a gestão dos bens artísticos e culturais pelas organizações públicas e privadas tornou-se um fator estratégico. Todavia, são poucos os estudos relacionando arte e gestão no Brasil. Em tese,

\footnotetext{
1 - Etimologicamente, a palavra "cultura, culturae" se origina do latim e se refere ao sistema agrário ou a agricultura, que indica o cultivo de plantas, ao ato de plantar ou mesmo ao desenvolvimento das atividades agrícolas. Na Antropologia, cultura pode ser conceituada como uma característica única do ser humano, 'relacionada ao tempo', de comunicação, vida social, e a qualidade cumulativa de interação humana, permitindo que as ideias, a tecnologia e a cultura material, sejam guardadas e compartilhadas entre diferentes grupos sociais. Enquanto na Sociologia, significa tudo aquilo criado pelo ser humano, como ideias, artefatos, costumes, leis, crenças morais, conhecimento, adquirido a partir do convívio social (SANTOS, 2020).
} 
uma explicação para essa carência está relacionada à pequena importância dada à gestão cultural nos cursos de graduação em Artes e Administração (JESUS, 2017; STORI e MARANHÃO, 2017; MARANHÃO e STORI, 2018).

Além disso, alguns pesquisadores mencionam que a gestão cultural é um campo, ainda, em formação e que carece da troca de informações sobre metodologias e estratégias de gestão. Os recentes cursos de formação acadêmica (bacharelados, pós-graduações, especializações e extensões) ainda são em número reduzidos no Brasil e pouco adequados à preparação prática dos estudantes com informações atualizadas e de caráter universal sobre a administração das organizações culturais e artísticas.

O tema "Arte e Gestão na Contemporaneidade: dilemas e obstáculos da formação ao mercado" é tão instigante e promissor que Evard e Colbert (2000) acreditam que a Gestão Cultural terá um grande espaço no século 21. Nota-se que a grande maioria dos artistas das diversas linguagens artísticas tem dificuldade em administrar a sua carreira, aceitar isso significa que uma pequena inabilidade ou falta de conhecimento na área pode colocar em risco todo um projeto ou a própria carreira. Portanto, observa-se no mercado, uma crescente procura por gestores e captadores de recursos, pois estas atividades requerem dedicação e conhecimentos sobre gestão e administração (DAVID, 2013; STORI e MARANHÃ̃, 2017; MARANHÃO e STORI, 2019a).

Com isso, na área da cultura, especificamente no que tange à gestão das organizações artísticas e culturais, por tratar-se de um campo de atuação muito recente, com poucas iniciativas de formação em comparação a outros campos, não existem discussões a respeito da problematização da formação em gestão cultural. Logo, por discutir a temática da formação em gestão para as organizações artísticas e culturais, o presente trabalho vai contribuir nessa lacuna pouco estudada (STORI e MARANHÃO, 2017; MARANHÃO e STORI, 2019a; MARANHÃO e STORI, 2019b).

De acordo com Ferreira (2015), verifica-se que a produção - empírica e científica, que tem o gestor das organizações culturais como foco principal - é pequena. Pouco se pesquisa sobre esse profissional, talvez isso possa ser explicado pela dualidade das atividades exercidas por ele, ou seja, na maioria dos casos é o próprio artista quem exerce o duplo papel de criador e gestor.

\section{ORGANIZAÇÕES ARTÍSTICAS E CULTURAIS}

Uma organização é caracterizada pela sua interação com o setor econômico, pela análise das suas finalidades e de sua missão, pela identificação de produtos, mercados e agentes do sistema (fornecedores, concorrentes, órgãos normativos e instituições afins). 
Não há na literatura nacional um conceito amplamente empregado para as Organizações Artísticas e Culturais, porém foram identificados dois diferentes conceitos que podem ser considerados análogos: equipamentos culturais ${ }^{2}$ e centros culturais. O primeiro diz respeito a edificações destinadas à prática cultural quanto a grupos de produtores culturais abrigados ou não, físicamente, numa edificação ou instituição. O segundo refere-se ao uso genérico para a designação do espaço destinado à promoção da cultura. Percebe-se que ambas as definições dizem respeito ao espaço em que a arte, ou a cultura, são promovidas, mas nenhuma delas relaciona esta promoção à gestão do equipamento ou do centro (STORI e MARANHÃO, 2017).

Todavia, de acordo com os apontamentos de Bilton (2006), as organizações culturais têm uma cultura gerencial distinta das organizações produtivas tradicionais, a qual se diferencia em três aspectos: autogestão e empreendedorismo; forma de estruturação da cadeia de valor; e a influência de valores não comerciais. A primeira dimensão refere-se à tradição de autonomia e trabalho individual, em que o trabalho criativo é desenvolvido por uma diversidade de artistas autônomos, integrados em redes de relacionamentos. Esses criadores atuam em projetos de duração definida e desempenham várias tarefas simultaneamente, tanto criativas quanto gerenciais. Na segunda dimensão, o trabalho criativo e a geração de valor da cadeia produtiva não estão concentrados em grandes empresas, mas dispersos em uma rede diversificada de profissionais e microempresas especializadas nas diversas atividades dos processos de criação, produção e distribuição de conteúdos criativos. Já a terceira dimensão, refere-se ao fato de que os produtos culturais têm dupla natureza: além de seu caráter econômico, são portadores de valor simbólico e conteúdo estético, o que introduz uma relação diferente com o mercado.

Refletindo sobre os conceitos estudados, percebe-se uma lacuna, pelo menos na bibliografia consultada: faltam estudos sobre organizações culturais no que diz respeito a sua administração e, dentro desta, da gestão da produção cultural.

Desta forma, torna-se necessário capacitar profissionais que possam atender as seguintes organizações e áreas:

- Área do Patrimônio Histórico Cultural: podem exercer atividades em museus, arquivos, bibliotecas, hemerotecas, filmotecas, espaços expositivos, dentre outros.

- Área de Artes Plásticas: os locais de trabalho são em galerias de arte, museus, fundações, centros culturais, centro de artesanato, dentre outros.

2 - O termo equipamento cultural se refere a “edificações destinadas a práticas culturais", servindo para designar organizações culturais das mais diversas tipologias como teatros, cinemas, bibliotecas, arquivos, galerias, espaços polivalentes, salas de concerto, museus, dentre outros. Serve de sinônimo para termos como casa de cultura, espaço cultural, complexo cultural, conjunto cultural, centro de cultura ou ponto de cultura (COELHO, 1997). 
- Área de Literatura e Editoração: festivais, prêmios, editoras, difusão e venda, dentre outros, são os principais espaços para atuar como gestores.

- de Artes Audiovisuais: os principais locais de atuação para esse setor são: museus da imagem e do som, filmotecas, museus, galerias de arte, fundações, rádio, televisão, produção audiovisual, novas tecnologias, dentre outros.

- Área da Cultura Popular e Tradicional: no âmbito da participação, ainda prevalece como espaço de manifestação às festas populares ou associações específicas, centro de artesanato.

Para Ferreira (2015), as organizações culturais precisam ser sistematicamente ajustadas às condições ambientais, sendo a organização de natureza sistêmica, isto é, um sistema aberto, com as variáveis institucionais apresentando um complexo inter-relacionamento entre si e o ambiente, com as variáveis ambientais funcionando como independentes, enquanto as variáveis organizacionais são dependentes do ambiente. Não há nada de absoluto nos princípios da organização. Os aspectos universais e normativos devem ser substituídos pelo critério de ajuste entre organização e ambiente. Dessa forma, a maioria das organizações culturais, a princípio, nasce da lógica “informal”, mas precisa se adaptar rapidamente para a sobrevivência, o que por si só já confere à gestão cultural propriamente dita um caráter particular.

Com isso, Hudson (1999) afirma que as organizações culturais estão em ascensão, tanto em número quanto em tamanho, e sua contribuição principal está na capacidade de representar o ponto de vista das pessoas, inovar e proporcionar um sentido de cidadania.

\section{FORMAÇÃO EM ADMINISTRAÇÃO - GESTÃO ${ }^{3}$}

Os primeiros cursos a ministrarem Administração no Brasil são do ano de 1902, em duas escolas particulares: no Rio de Janeiro, na Escola Álvares Penteado, e em São Paulo, na Academia de Comércio. No entanto, o ensino não era regulamentado, o que ocorreu somente em 1931, com a criação do Ministério da Educação e a estruturação do ensino em todos os níveis (NICOLINI, 2003).

Desde a regulamentação da Administração como profissão, que ocorreu em 1965, por intermédio da Lei Federal n. 4.769, que regula e dispõe sobre o exercício da profissão de "técnico em administração", o conselho Federal de Educação já realizou três fixações do currículo mínimo da

\footnotetext{
3 - Ato ou efeito de gerir; administração, gerência. O termo gestão tem sua origem na área da Administração de Empresas. Contudo, com a evolução das escolas de gestão dos Estados Unidos o termo passou a ser utilizado também em outras áreas do conhecimento e, como conseqüência, a ser dominado por psicólogos, sociólogos, biólogos, matemáticos, estatísticos etc; tornando-se, assim, interdisciplinar. De acordo com Chiavenato (1993), a gestão é um fenômeno universal do mundo moderno. Cada organização requer a tomada de decisões, a coordenação de múltiplas atividades, a condução de pessoas, a avaliação do desempenho dirigido a objetivos previamente determinados, a obtenção e alocação de diferentes recursos etc. Numerosas atividades administrativas desempenhadas por diversos administradores, voltadas para tipos específicos de áreas e problemas, precisam ser realizadas em cada organização.
} 
formação desta profissão. Isso ocorreu em 1966, com a primeira estruturação do conteúdo mínimo e a duração dos cursos de administração no Brasil, e em 1993, com o trabalho conjunto da Associação Nacional dos Cursos de Graduação em Administração (ANGRAD) e o Conselho Federal de Administração (CFA) para a aprovação do novo currículo.

No entanto, em 2005, ocorre a criação do terceiro currículo mínimo, vigente até hoje, segundo o qual o Curso de Graduação em Administração deve ensejar, como perfil desejado do formando, capacitação e aptidão para compreender as questões científicas, técnicas, sociais e econômicas da produção e de seu gerenciamento, observados níveis graduais do processo de tomada de decisão, bem como para desenvolver gerenciamento qualitativo e adequado, revelando a assimilação de novas informações e apresentando flexibilidade intelectual e adaptabilidade contextualizada no trato de situações diversas, presentes ou emergentes, nos vários segmentos do campo de atuação do administrador (NICOLINI, 2003).

Ou seja, a formação em administração enfatiza fundamentalmente conteúdos disciplinares funcionalistas, tais como o taylorismo / fordismo / toyotismo, mercadologia, produção, economia, finanças, contabilidade e relações humanas como uma variável. Embora tenha ocorrido a incorporação de campos como economia, sociologia, política, psicologia e direito, a ciência da administração segue a lógica de coordenação de conhecimentos parcelados, em consonância com a divisão do trabalho industrial.

Isto é, o conteúdo curricular é estruturado a partir do ideário da "gerência científica", assim, o ensino serve tão somente para a produção em massa de bacharéis, e as escolas de administração, como estão estruturadas, mais se parecem com fábricas, que recebem a matéria-prima (o aluno) e a transformam, ao longo da linha de montagem (o currículo pleno), em produto (o administrador).

Essa visão fragmentada e segmentada é a responsável pela transmissão de uma ideologia do "management"4 , dos conceitos de planejamento, organização, coordenação e controle e pelo ensino da política de negócios atualmente conhecida como planejamento estratégico.

Para Nicolini (2003) é fato que a grande maioria das escolas de Administração no Brasil não tem inovado quando o assunto é o bacharelado. A ausência de originalidade das propostas, aliado à rigidez da lei que regulamenta a área, traduz-se em uma formação homogênea e sem espaço de destaque para transformações.

\footnotetext{
4 - Conjunto de conhecimentos referentes à organização e à gestão de uma empresa; administração.
} 


\section{FORMAÇÃO EM ARTES COM GESTÃO}

O processo de formação do artista contemporâneo deve ser definido a partir de um conceito preciso de seu papel na sociedade. Tal conceituação implica discutir o espaço ocupado, hoje, pela arte no corpo da cultura e, mais, implica verificar a relação, decorrente, entre o processo formativo do artista e sua real possibilidade de atuação (RESENDE, 2005; ARRUDA e DEUS, 2021).

No Brasil, a formação em artes é ampla, mas boa parcela das instituições de ensino superior apresenta em seus currículos formação em uma das seguintes linguagens - Música, Teatro, Dança e Artes Visuais, bem como nas quatro linguagens e em licenciatura. No caso das artes visuais o profissional está ligado à difusão da arte e da cultura por meio de diferentes linguagens artísticas como a pintura, a escultura, as multimídias, o desenho, entre outras.

Assim, em se tratando da formação do artista visual é possível inferir que seu espectro de formação poderá transformá-lo não apenas em artista, mas em um profissional capaz de atuar em museus, arte educador, galerias, teatros, na área de pesquisa e curadoria de arte. Eles também podem encontrar espaço profissional na televisão, no cinema, no circo e até na indústria, trabalhando com linhas de produto e estampas.

No Brasil, se forem analisados os currículos de graduação e pós-graduação dos cursos de artes dificilmente serão identificadas disciplinas que abordem o tema gestão cultural. Se tomados os cursos considerados referências na formação no campo das artes, tais como, das universidades públicas: Universidade Estadual de Campinas (UNICAMP), Universidade Estadual Paulista "Júlio de Mesquita Filho" (UNESP), Universidade Federal da Bahia (UFBA) e da Universidade de São Paulo (USP); bem como nas instituições particulares como: Fundação Armando Álvares Penteado (FAAP) e o Centro Universitário Belas Artes de São Paulo (Belas Artes), não é possível identificar alguma disciplina relacionada direta ou indiretamente à preparação de profissionais para gestão cultural.

Tal assertiva pode ser ampliada para os cursos de outras grandes instituições que possuem cursos de graduação e pós-graduação relacionados à área de Artes, dentre as quais a Universidade Federal do Rio de Janeiro (UFRJ), Universidade Federal do Rio Grande do Sul (UFRGS), Universidade Estadual de Minas Gerais (UEMG), Universidade Estácio de Sá e a Universidade do Estado do Rio de Janeiro (UERJ).

Essa lacuna na formação dos artistas dificulta o ingresso no mercado de trabalho, pois a demanda atual requer a presença de um profissional específico que tenha conhecimentos a respeito dos processos constitutivos da cadeia produtiva do setor e que, além da noção das etapas básicas de trabalho em gestão cultural, como criação, produção e distribuição, considere primordialmente para o desenvolvimento de ações e iniciativas culturais as etapas de pesquisa, planejamento e avaliação. 
Consequentemente, a falta de programas de treinamento, disciplinas e ferramentas pedagógicas adequadas para a capacitação desse perfil de empreendedor criativo durante a graduação em artes geram obstáculos no ingresso ao mercado de trabalho.

Todavia, Santos (2011) enfatiza que não se trata apenas de treinar o aluno para a gestão ou de obrigá-lo a aceitar a realidade de mercado como uma regra a ser seguida. Trata-se, pois, de prepará-lo para o diálogo, fazê-lo conhecer também as necessidades e as soluções inerentes ao processo de criação teatral como empreendimento. Dentro desse aprendizado, o artista desenvolve argumentos e práticas para interferir na dita realidade, transformando-a como agente produtivo.

\section{FORMAÇÃO EM GESTÃ̃ CULTURAL}

A área cultural, na perspectiva econômica, engloba um conjunto diversificado de empresas, organizações, instituições e profissionais, que realizam atividades de criação, produção, comercialização, distribuição, difusão e preservação de bens e serviços culturais. Diante dessa diversidade, vários autores têm discutido as designações utilizadas para identificar as atividades culturais (LIMEIRA, 2008).

A gestão cultural pode ser considerada como nova disciplina da gestão tradicional e empresarial (EVARD e COLBERT, 2000). Este termo vem se consolidando no Brasil, sendo objeto de pesquisas e debates acadêmicos ou não. O reconhecimento do campo da gestão cultural advém da importância econômica e social do segmento cultural para o país e sua contribuição para a empregabilidade de pessoas e seus impactos nos indicadores econômicos nacionais.

No Brasil, a gestão cultural é tema recente em estudos e práticas acadêmicas, fazendo com que as atribuições do profissional da cultura sejam ainda pouco conhecidas. Devido a uma reestruturação do mercado cultural brasileiro, há demanda por profissional qualificado e específico para lidar com atividades culturais.

Em meados da década de 1990, iniciou-se a estruturação de cursos acadêmicos em algumas regiões do país para formação de produtores e gestores culturais. Como exemplo, os cursos de graduação em Produção Cultural da Universidade Federal Fluminense (UFF) e da Universidade Federal da Bahia (UFBA), iniciados nessa década.

Uma alternativa para capacitação dos profissionais do setor criativo tem sido a de investirem em MBA (Master in Business Administration). No caso de São Paulo existe, por exemplo, o MBA em Gestão Cultural do Centro de Pesquisa e Documentação de História Contemporânea do Brasil, da Fundação Getúlio Vargas (CPDOC/FGV) e na Bahia ocorreu recentemente a implantação do MBA em 
Gestão do Patrimônio Cultural e Material pela Business School Maurício de Nassau (FLACH e ANTONELLO, 2011).

Em 2000, o SEBRAE ${ }^{5}$ lançou o Programa Empreendedor Cultural, um conjunto de iniciativas que visam a capacitação, o desenvolvimento e a expansão dos negócios da área da cultura. Esse programa visa formar uma Rede de Agentes Culturais, que são pessoas ligadas à cultura, como artistas, produtores, educadores, para que estes possam se relacionar e se apoiar mutuamente.

No que diz respeito às ações governamentais, até o ano de 2004, o único programa do Governo que atendia (mesmo que parcialmente) à capacitação de gestores culturais era o programa "Gestão da Política e Cultura". A partir de 2004 foi criado o programa "Cultura, Educação e Cidadania”, que tinha como um dos principais objetivos a capacitação de gestores culturais, conforme consta como um dos objetivos específicos do programa: “(a) a formação de gestores e empreendedores culturais; (b) formação artística e para o desenvolvimento humano e social; (c) capacitação técnica e aperfeiçoamento profissional”. Em 2005 foi criado o programa "Cidadania, Identidade e Diversidade", mantendo como um dos focos a implantação de espaços culturais integrados e cursos de capacitação nos centros urbanos e cidades que não dispõem de equipamentos culturais coletivos (LIMEIRA, 2008).

Outra iniciativa para apoio e desenvolvimento de empreendimentos culturais é o programa de incubadoras culturais, ligadas à ANPROTEC (Associação Nacional de Entidades Promotoras de Empreendimentos Inovadores). No Rio de Janeiro, a PUC-Rio e o Instituto Gênesis iniciaram o Programa de Formação de Empreendedores Culturais, que inclui uma incubadora cultural, a qual se constitui em um programa em que empreendimentos e projetos nascentes voltados para a área cultural associam-se ao Instituto Gênesis, obtendo acesso à rede de serviços de apoio do Instituto e aos ativos intelectuais da Universidade (LIMEIRA, 2008).

Na Inglaterra, desde 1997, há um esforço das universidades em oferecerem cursos de formação e especialização desenvolvidos para capacitar empreendedores culturais. Como exemplo, na Universidade de Warwick, a professora Sally Kellet considera que os princípios e processos subjacentes aos empreendimentos culturais não são amplamente conhecidos, tornando-se necessário maior investimento em pesquisas sobre seus processos econômicos e gerenciais (KELLET, 2006).

\footnotetext{
5 - O Serviço Brasileiro de Apoio às Micro e Pequenas Empresas - SEBRAE - elaborou o Programa Sebrae do Artesanato. Disponível em http://www.artesanatobrasil.com.br/frameset0.htm. Acesso em 11/03/2018.
} 


\section{MÉTODOS}

A pesquisa é caracterizada como exploratória e explicativa, pois se propõe a compreender um fenômeno sobre o qual ainda se dispõe de pouca informação. Para atingir os objetivos propostos a pesquisa foi realizada em três etapas:

1) Primeira etapa: revisão bibliográfica sistemática para melhor esclarecimento dos conceitos e definições sobre gestão cultural e o papel do gestor nas organizações, bem como verificar o estado da arte. Foi realizada uma busca na base $S_{\text {Sell }}$, base de dados brasileira que concentra artigos publicados a partir de 2000, das áreas de Administração, Contabilidade e Turismo. O diferencial desta base, e um dos motivadores da escolha por trabalhar com ela, está no fato de que todos os artigos da base possuem acesso liberado. Assim, a Spell consiste em uma ferramenta virtual que agrega a produção científica disponibilizada eletronicamente pelos periódicos associados, reunindo artigos científicos, resenhas, editoriais, notas bibliográficas, casos de ensino, debates entre outros documentos. A escolha por essa base de dados aconteceu pela possibilidade de filtragem dos artigos conforme critérios específicos. Assim, procedeu-se a coleta dos dados secundários, através da busca dos seguintes termos no título, resumo e palavras-chave: "organizações culturais"; "organizações artísticas" e "formação em administração".

2) Segunda etapa: coleta de dados de arte e junto aos sites das Instituições de Ensino Superior que possuem cursos nas áreas de administração e artes para identificação e mapeamento da formação em Gestão Cultural. As informações obtidas diretamente dos sites das Instituições foram tabuladas com o auxílio do programa Microsoft Excel.

3) Terceira etapa: entrevista com professores e especialistas das áreas de arte e gestão, bem como graduados em administração e artes. Nesta etapa foi utilizada a amostragem em bola de neve, pois se buscou estudar determinado grupo. Dessa forma, a grande vantagem dessa amostragem é o fato de os entrevistados serem recrutados a partir da relação pessoal das pessoas dispostas a indicar contatos, o que pode emprestar confiabilidade ao entrevistador. Assim, foram obtidos 22 entrevistados com formação nas áreas de administração, artes, comunicação social e outras (direito, química industrial e biologia).

\footnotetext{
6 - A biblioteca eletrônica SPELL - Scientific Periodicals Electronic Library, é um repositório de artigos científicos que proporciona acesso gratuito à informação técnico-científica.
} 


\section{ANÁLISE DOS RESULTADOS E DISCUSSÃO}

Foram entrevistadas 22 pessoas com o seguinte perfil: 55\% com formação em Administração; 18\% com formação na área de Artes; 9\% com formação em Comunicação Social; e 18\% com formação em outras áreas do conhecimento, porém com envolvimento na área de artes ou eventos culturais.

Em relação ao nível de escolaridade dos entrevistados destaca-se que: $41 \%$ possuem apenas graduação; 32\% com pós-graduação em nível de mestrado; 18\% com pós-graduação em nível de doutorado; e 9\% com pós-doutoramento concluído.

Sobre a gestão no contexto atual uma entrevistada registra que é difícil pensar em organizações culturais e artísticas pelo simples entendimento de que muitas ações são desfocadas e descontextualizadas da realidade em que a população está inserida.

\footnotetext{
"Pelo pouco entendimento que tenho, a arte contemporânea não é conhecida como deveria ser e por isso, muitas ações culturais são banais, fúteis, distorcidas e sem fundamento algum com o que realmente se deveria chamar de arte, principalmente no que se refere a representar a cultura brasileira" (Entrevistada 5).
}

Cabe ressaltar que tal percepção corrobora com a pouca importância dada às organizações culturais e artísticas. Tal assertiva encontra eco nas referências bibliográficas ao não obtermos uma definição ou conceito para essas organizações. Além disso, quando pensamos em arte, geralmente dissociamos das atividades culturais, principalmente aquelas manifestações populares.

Um dos entrevistados ressalta que "A cultura é muito diversa e segmentada, sendo valorizada àquelas associadas a uma determinada região, como a nordestina ou gaúcha, por exemplo. Há gestores que a incentivam através de organizações governamentais ou não, utilizando as ferramentas administrativas mais adequadas em cada situação" (Entrevistado 22).

Destaca-se que $100 \%$ dos entrevistados entendem que seja relevante estudar as organizações culturais e artísticas em um país como o Brasil - de grande riqueza e diversidade cultural.

Sobre a formação dos entrevistados em relação à gestão cultural, ficou registrado que 95\% das pessoas não tiveram uma disciplina voltada para a gestão das organizações culturais e artísticas e apenas 5\% tiveram formação. Levando-se em consideração apenas os administradores e artistas, $100 \%$ dos entrevistados afirmaram não ter recebido formação na área de gestão das organizações culturais e artísticas. Essa perspectiva condiz com os apontamentos apresentados na revisão bibliográfica em relação à formação de administradores e nas áreas de artes.

Isto significa que a formação em administração enfatiza fundamentalmente conteúdos disciplinares funcionalistas, mercadologia, produção, economia, finanças, contabilidade e relações humanas como uma variável. 
Tal entendimento é corroborado por Nicolini (2003, p. 47), ao apontar que nos primeiros períodos da formação do administrador estão as disciplinas da formação básica e instrumental, a base que sustentará o todo:

\footnotetext{
"Economia, Direito, Matemática, Contabilidade, Filosofia, Psicologia, Sociologia e Informática. Espera-se, nessa formação, fundamentar no futuro administrador a compreensão e as aplicações das ciências sociais que dão base à Administração, bem como o desenvolvimento das habilidades matemáticas necessárias para quantificar e especular. É uma preparação necessária, segundo a lógica presente na lei, para a próxima fase. Nos períodos seguintes, são ministradas as disciplinas da formação profissional que tornarão o administrador capaz de operar dentro de sua área: Teorias da Administração, Administração Mercadológica, Administração de Recursos Humanos, Administração de Produção, Administração Financeira e Orçamentária, Administração de Recursos Materiais e Patrimoniais e Organização, Sistemas e Métodos. Nessa formação, trabalha-se para construir no estudante o domínio das áreas técnicas consideradas como de âmbito exclusivo dos administradores e que compõe o campo do saber administrativo propriamente dito".
}

Apesar de 30\% dos entrevistados com graduação em administração terem informado que tiveram conhecimentos relacionados a empreendedorismo, ficou registrado que não houve relação com conteúdos atinentes à gestão de organizações culturais e artísticas.

Tal afirmação também endossa o debate em relação a uma formação focada apenas nas indústrias convencionais e no comércio, deixando de lado as organizações voltadas à cultura, portanto não enfatizando questões locais na formação dos administradores, apenas a perpetuação de um currículo padronizado e generalista. Ratificando desta forma, que a matéria-prima (o aluno) é transformada na linha de montagem (o currículo pleno) em produto comum (o administrador).

A partir dessa lógica, Paulo Freire cita que:

O estudante como produto não transforma o mundo, mas antes tende a ele se adaptar,
anulando ou reduzindo dramaticamente seu poder criador. Dissocia-se de seu papel como
indivíduo, relegando-o a um segundo plano, no qual sua responsabilidade como agente de
mudança está alijada do exercício profissional. Torna-se um ingênuo (FREIRE, 1987, p. 69).

Um dos entrevistados (01) aponta que o mercado requer gestores que estejam atentos não apenas aos aspectos subjetivos da cultura e dos bens simbólicos, mas também às regras de economia, marketing e política (MARANHÃO e STORI, 2019a; MARTINS, 2021).

Cabe destacar que não há conteúdos que versem sobre ferramentas de gestão nos cursos das áreas de arte, apesar de alguns profissionais dessas áreas serem direcionados após a formação para a indústria cultural, ou seja, para companhias teatrais ou circenses, bem como museus, e outras organizações como Escolas de Samba (STORI e MARANHÃO, 2017; MARANHÃO e STORI, 2019b). 
Quando os entrevistados foram indagados se havia preocupação com a gestão das organizações culturais e artísticas ou gestão cultural, ficou registrado que $77 \%$ acreditavam que não e apenas $23 \%$ corroboram o entendimento que há uma preocupação com essas organizações. Porém, 77\% dos entrevistados concordam que a gestão das organizações culturais e artísticas é um campo em formação no Brasil e apenas 23\% discordam dessa afirmação. Em contrapartida, $91 \%$ dos entrevistados registram que há uma carência de estudos sobre as organizações culturais e artísticas.

Em relação às possíveis contribuições das ferramentas de gestão para o sucesso profissional dos artistas, um dos entrevistados com formação na área de artes registrou:

No contexto atual, as formas de divulgação, marketing, comercialização estão totalmente se alterando, sendo difícil até para os especialistas terem certezas sobre um futuro próximo. Assim, o contexto da arte também está inserido nesse contexto maior, que denominam de pósdigital. Muitas formas de comércio existentes até agora vão sumir rapidamente, em um ou dois anos e talvez para o artista seja até mais fácil vender suas obras pela Amazon, Alibaba etc. (Entrevistado 20).

Alguns entrevistados afirmaram que valorizam a formação autodidata na área cultural, pois a formação convencional não se mostra capaz de suprir, de modo sistemático, as necessidades de um mercado especializado que exige profissionais cada vez mais capacitados e qualificados, em detrimento daqueles que realizam seu ofício somente de forma administrativa.

\section{CONSIDERAÇÕES FINAIS}

A pesquisa, em andamento, apresenta seus resultados preliminares. A partir dos dados obtidos e analisados é preciso que sejam reavaliados os currículos dos cursos de arte e administração, pois temas como desenvolvimento de carreira na área cultural, elaboração de plano de negócios, negociação, gestão de pessoas criativas, fontes alternativas de financiamento, gestão de redes de negócios culturais, gestão e controle financeiro, entre outros, deveriam fazer parte da formação de administradores e artistas.

Destaca-se que é indispensável ao exercício da gestão cultural a capacidade de se perceber que, em termos das leis da economia, os bens culturais são diferentes dos bens econômicos em geral. Em consequência, é preciso entender que, as funções gerenciais na cultura não são as mesmas de outros setores e por isso devem ser ministradas na formação dos administradores e artistas. O marketing cultural, por exemplo, não é uma extensão pura e simples do marketing que faz vender produtos como refrigerantes ou automóveis. 
A formação para as organizações culturais e artísticas é necessária para que possamos modificar a gestão das atividades culturais no Brasil e sua transformação deve ocorrer nos cursos de graduação, pois os gestores culturais são as figuras centrais para que esse quadro se modifique.

Os gestores, diferentemente de meros administradores, não só agem em prol da produção dos bens culturais, a parte sensível dessa cadeia, mas cuidam para que o acesso a eles se transforme em realidade. Esses profissionais, contudo, ainda são raros no Brasil. Sua formação é uma necessidade urgente detectada por poucos e bons especialistas da área em todo o país.

Como limitação da pesquisa aponta-se a baixa quantidade de entrevistados. Porém, a técnica empregada - bola de neve - é não probabilística e assim, não garante a representatividade. Destarte, recomenda-se que seja encontrado o ponto de saturação, pois tal ponto é atingido quando os novos entrevistados passam a repetir os conteúdos já obtidos em entrevistas anteriores, sem acrescentar novas informações relevantes à pesquisa.

Recomenda-se a continuação da pesquisa e a realização de outros estudos que possam identificar os cursos de Administração ou Artes que possuem disciplinas versando sobre: empreendedorismo, gestão de pessoas, planejamento estratégico e marketing de forma a compreender como tais conteúdos possam contribuir com a formação dos gestores culturais. 


\section{REFERÊNCIAS BIBLIOGRÁFICAS}

ARRUDA, T. M. B. .; DEUS, A. I. S. . Educação estética: um percurso, uma trajetória, um convite a arte. Latin American Journal of Development, v. 3, n. 3, p. 1633-1641, 25 Jun. 2021.

BILTON, C. Cultures of Management: Cultural Policy, Cultural Management and Creative Organisations. Centre for Cultural Policy Studies, University of Warwick, Inglaterra, 2007.

CHIAVENATO, I. Introdução à teoria geral da administração. $4^{\circ}$ ed. São Paulo: Makron Books, 1993.

COELHO, T. Dicionário crítico de política cultural. São Paulo: Iluminuras, 1997.

DAVID, J. G. Gestão teatral: iniciando uma Companhia Profissional. Trabalho de Conclusão de Curso. Graduação em Artes Cênicas da Universidade Federal de Santa Catarina, 2013. Disponível em: https://repositorio.ufsc.br/bitstream/handle/ 123456789/126105/TCC.pdf?Se quence=1. Acesso em: 28 de janeiro de 2018.

EVARD, Y.; COLBERT, F. Arts Management: A New Discipline Entering the Millennium? International Journal of Arts Management, vol. 2, no. 2, 2000, p. 4-13.

FERREIRA, C. R. A gestão e o gestor cultural: uma análise de características. Centro de Pesquisa e Formação, no 1, nov. 2015.

FLACH, L.; ANTONELLO, C. S. Organizações culturais e a aprendizagem baseada em práticas. CADERNOS EBAPE. BR, v. 9, nº 1, artigo 9, Rio de Janeiro, Mar. 2011.

FREIRE, P. Pedagogia do Oprimido. Rio de Janeiro: Paz e Terra, 1987.

HUDSON, M. Administrando organizações do terceiro setor: o desafio de administrar sem receita. São Paulo: Makron Books, 1999.

JESUS, L. C. A formação em gestão cultural e a ideia de administração. Dissertação (mestrado) Universidade Federal de Santa Catarina, Centro Sócio-Econômico, Programa de Pós-Graduação em Administração, Florianópolis, 2017.

KELLET, S. A Picture of Creative Entrepreneurship: Visual Narrative in Creative Enterprise Education. National Council for Graduate Entrepreneurship, Working Paper 043/2006. Disponível em http://www.ncge.org.uk/communities/index.php. Acesso em: 28 de janeiro de 2018.

LIMEIRA, T. M. V. Empreendedor Cultural: Perfil e Formação Profissional. Anais...IV ENECULT Encontro de Estudos Multidisciplinares em Cultura - Faculdade de Comunicação/UFBa, SalvadorBahia-Brasil, 28 a 30 de maio de 2008. Disponível em: https://s3.amazonaws.com/academia.edu.documents/34550268/gestao_de_ empreendimentos_culturais_1.pdf?AWSAccessKeyId=AKIAIWOWYYGZ2Y53UL3 A\&Expires $=1538238295 \&$ Signature $=$ RP2tydzWYQAAoRsDMnI7mAzrq2k\%3D\&responsecontent-disposition=inline $\% 3 \mathrm{~B} \% 20$ filename\%3DGestao_de_empreendimen tos_culturais_1.pdf. Acesso em: 20 de julho de 2018. 
MARANHÃO, R. A.; STORI, N. Arte e Gestão na contemporaneidade: dilemas e obstáculos da formação ao mercado. Projeto de Pesquisa de Pós-Doutoramento apresentado ao Programa de PósGraduação em Educação, Arte e História da Cultura da Universidade Presbiteriana Mackenzie, 2018.

MARANHÃO, R. A.; STORI, N. Merchandising no the voice kids: quais as marcas vinculadas ao reality show infantil?. Brazilian Journal of Development, v. 5, n. 5, p. 3931-3944, 2019a.

MARANHÃO, R. A.; STORI, N. Gestão e arte nas escolas de samba: algumas observações e análises. Brazilian Journal of Development, v. 5, n. 3, p. 1999-2011, 2019b.

MARTINS, R. R. A terceira linguagem no cross-cultural marketing: The third language in crosscultural marketing. Latin American Journal of Development, v. 3, n. 5, p. 2965-2976, 22 Sep. 2021.

NICOLINI, A. Qual será o futuro das fábricas de administradores? Revista de Administração de Empresas, vol.43, no.2, São Paulo - Apr./June 2003.

RESENDE, J. Formação do artista no Brasil. Revista ARS (São Paulo). Vol.3, n.5, pp.22-29, 2005. ISSN 1678-5320. http://dx.doi.org/10.1590/S1678-53202005000100002.

SANTOS, G. M. Sobre requisitos de formação superior em artes cênicas: o artista como empreendedor. Revista "O Teatro Transcende" do Departamento de Artes - CCE da FURB - ISSN 2236-6644. Blumenau, v. 16, n. 2, p. 03-14, 2011.

SANTOS, A. M. O conceito de cultura em foco. Latin American Journal of Development, v. 2, n. 4, p. 122-128, 17 Aug. 2020.

STORI, N.; MARANHÃO, R A. Bens culturais na Marinha do Brasil: um diálogo entre gestão e arte. Mouseion, n. 25, p. 53-73, 2017.

VALENTE, R.; SERAFIM, M. C.; ALVES; M. A.; BENDASSOLLI, P. F. Gestão de organizações culturais. RAE, Vol. 47 - nº 2, 2007. 